\title{
Diplomacia cultural: uma arena de embates na Ditadura Militar
}

\author{
Rogério de Souza Farias \\ Bruno Zétola
}

\begin{abstract}
Resumo: A análise da diplomacia cultural brasileira nos anos iniciais da Ditadura Militar (1964-85) permite identificar tensões entre interlocutores divergentes e entre correntes procedimentais distintas sobre como o Estado deveria projetar sua mensagem no sistema internacional. A despeito de seus esforços, a Ditadura não conseguiu pacificar completamente esses embates ou transformar a diplomacia cultural em mera propaganda do regime. A ocorrência de continuidades e contradições na área sugere ser a diplomacia cultural um campo disruptivo, inercial e errático.
\end{abstract}

Abstract: An analysis of Brazilian cultural diplomacy in the beginning of the military dictatorship (1964-1985) sheds light on the tensions that emerged between diverging interlocutors and different procedural currents on how the Brazilian State should project its message in the international system. Despite its efforts, the dictatorship was never able to pacify these conflicts, nor did it transform cultural diplomacy into regime propaganda. The coexistence of continuity and contradiction in cultural diplomacy suggests that it is a disruptive, inertial and erratic field. 
Rupturas da ordem política são temas que fascinam historiadores e cientistas sociais, pois representam ocasiões privilegiadas para a análise do papel de indivíduos e de estruturas institucionais em embates por continuidades e rupturas. O Golpe de Estado de 1964 é um desses momentos na história brasileira, considerado por muitos como forte inflexão na política externa brasileira, que passaria a se caracterizar por um viés anticomunista, pró-americano, conservador e apoiador de uma agenda econômica liberal (Bado, 2006, Silva, 2004, Cervo and Bueno, 2008, pp. 368373, Martins, 1975, pp. 58-76). Nesse contexto, este artigo examinará os efeitos do Golpe e da Ditadura até 1970 para a diplomacia cultural brasileira, em abordagem que considera a cultura campo específico, embora interdependente da macroestrutura política.

Embates envolvendo diferentes concepções sobre como essa política pública deveria ser conduzida verificam-se desde a década de 1930 e refletem entendimentos distintos sobre como o Estado brasileiro deveria projetar sua imagem no mundo. A partir da análise de documentos internos do Ministério das Relações Exteriores (Itamaraty), sobretudo as séries telegráficas e memoranda, sustenta-se que a ruptura do regime político em 1964 não levou imediatamente a uma pacificação das clivagens pré-existentes da diplomacia cultural brasileira. Houve, ao contrário, um movimento de resistência por parte de setores da chancelaria brasileira com vistas a manter os parâmetros da diplomacia cultural a despeito das pressões do aparato repressivo.

Deve-se notar que, durante a ditadura, a diplomacia atuou na área cultural de várias formas. Este artigo não tem como objetivo examinar todas essas ações. Será priorizada aqui a análise da difusão cultural em detrimento da promoção do idioma e da cooperação educacional, dado que vários conflitos no setor permitem analisar melhor os processos de continuidade e de ruptura. $\mathrm{O}$ artigo inicia com breve discussão sobre os debates no campo da diplomacia cultural no período anterior ao Golpe de 1964. Segue-se uma análise da correção de rumos que os novos donos do poder buscaram dar para a área. Apresentam-se, por fim, elementos que demonstram a resistência a essas pressões. Esse vivo embate entre diferentes perspectivas no âmbito da condução da diplomacia cultural sugere certa autonomia da área, alta discricionariedade de seus operadores e grande grau inercial das políticas públicas, especialmente das que se relacionam a áreas disruptivas como a cultura.

\section{Diplomacia cultural}

Definir o campo da diplomacia cultural não é tarefa simples nem consensual. Os termos desse debate são vastos, assim como as controvérsias. Em importante artigo a respeito do tema, Ang, Isar e Mar assinalam que "há uma nítida falta de clareza na forma como a noção é usada, sobre exatamente o que sua prática envolve, por que ela é importante e como como ela funciona" (Ang, Isar, \& Mar, 2015, p. 365). São volatilidades tributárias da complexidade de ambos os binômios do termo "diplomacia cultural". Cultura já é uma noção altamente complexa, que, dependendo da 
chave interpretativa, pode abranger uma ampla gama de fenômenos, desde as artes eruditas até os hábitos e valores cotidianos de grupos específicos da sociedade humana. Do mesmo modo, não há consenso sobre a natureza e o propósito da diplomacia, nem sobre seus atores legítimos, mesmo assumindo-se um uso não metafórico do termo.

A despeito dessa plêiade de possibilidades, sobressaem na vasta bibliografia a respeito da matéria algumas tendências que permitem uma aproximação operativa ao conceito. Se "a definição de diplomacia cultural é quase tão variada quanto o número de países que assumem seu uso" (Zamorano, 2016, p. 169), pode-se sugerir que se trata de uma política pública com o objetivo de desenvolver uma narrativa nacional, ou, em outras palavras, de "contar sua história para o resto do mundo" (Cummings, 2009, p. 1). ${ }^{1}$ Nessa direção, Berridge e Lloyd, na mais recente edição de seu dicionário, apresentam uma acepção assaz funcional de diplomacia cultural que se adequa ao escopo desta contribuição: “a promoção, no exterior, das realizações culturais de um Estado, com ênfase especial em línguas e artes, mas abrangendo também ciência e tecnologia" (2012, p. 87-88). Outros teóricos convergem para essa tendência, ao aduzirem conceitos relevantes, como "o processo colaborativo que cria e sustenta interações culturais oficiais e informais entre nações" (Falk, 2010, p. 7-8) voltado "para apoiar os objetivos de política externa de governos (...), geralmente envolvendo direta ou indiretamente o Ministério das Relações Exteriores e abrangendo amplo arco de manifestações culturais do Estado que o governo representa, direcionado a uma população mais ampla e também a elites" (Mark, 2010, p. 64-65). No Brasil, uma definição bastante difundida - e reveladora de uma práxis social, já que proposta por um ex-diretor do Departamento Cultural do Itamaraty - sublinha "a utilização específica da relação cultural para a consecução de objetivos de natureza não somente cultural, mas também política, comercial ou econômica" (Ribeiro, 2011, p. 33 e 37).

Em todas essas acepções, nota-se ser a identificação de uma cultura nacional adequada ao atendimento dos objetivos da política externa o elemento que confere coerência ao campo da diplomacia cultural, independentemente das diferentes perspectivas a respeito do que consistiria essa cultura nacional e de como ela poderia produzir efeitos nas relações internacionais. Conforme assinalou Clarke (2020, p. 6), um ponto fundamental para o estudo da diplomacia cultural "é compreender como a construção discursiva do campo político está sujeita a mudanças de compreensão, tanto da natureza da cultura quanto de seu valor para a política, e de como essas mudanças foram negociadas por uma série de atores."

Embora conceitualmente distinta da propaganda e da diplomacia pública, voltadas para moldar uma imagem do país no exterior por campanhas de informação, a diplomacia cultural

\footnotetext{
${ }^{1}$ Mesmo os opositores de uma abordagem que privielgia o protagonismo dos estados nacionais, no campo da diplomacia cultural, convergem na perspectiva de que se trata de uma prática social que visa a veicular uma narrativa nacional. É o caso, por exemplo de Patrícia Goff, que sugere ser possível "contar outra história sobre um país" que "pode ser uma história diferente do que a política oficial veicularia" (Goff, 2013, p. 3).
} 
confunde-se e choca-se, muitas vezes, com essas dimensões. Isso decorre de atividades artísticas comumente voltarem-se para a crítica do Estado, das elites e das condições econômicas e sociais sinalização oposta à propaganda e à diplomacia pública, que buscam projetar uma imagem sem contradições e convergente com padrões aspiracionais de status internacional. $O$ advento da Ditadura militar brasileira apresenta-se, nesse contexto, como momento privilegiado para se analisar os embates a respeito das mudanças na narrativa nacional que a diplomacia cultural brasileira deveria veicular.

Observam-se, no Brasil, desde a década de 1930, dois intensos embates entre diplomatas envolvidos na área cultural. ${ }^{2}$ O primeiro refere-se à função social da produção cultural. Muitos entendiam a cultura como elemento de reflexão e engajamento social capaz de formar opiniões e, portanto, passível de ser subordinada ao mundo da política. Essa concepção aproxima a diplomacia cultural da propaganda. É justamente com essa perspectiva que Rui Ribeiro Couto propôs, em 1934, a criação do "Serviço de Expansão Intelectual" no Itamaraty. O objetivo seria fazer "discretamente" a propaganda dos valores literários do Brasil no estrangeiro, retirando-se, o mais que possível, o caráter ostensivo de "propaganda oficial" aos trabalhos (Couto, 1934).

Para representantes desse grupo, o papel da diplomacia cultural era "mostrar o progresso, o dinamismo, bem como os aspectos mais interessantes da atividade cultural do Brasil" (Guimarães, 1952). Nessa visão, era responsabilidade dos diplomatas zelar pela imagem do país no exterior, vetando e criticando iniciativas artísticas que pudessem de alguma maneira ser avaliadas negativamente, ainda que restasse claro o elemento da representatividade nacional. Em 1949, por exemplo, Roberto Mendes Gonçalves, chefe da Divisão de Cooperação Intelectual (DCl), fez acerbas críticas à política de aquisição e edição de álbuns para a divulgação da música popular brasileira no exterior - seria inferior a outros gêneros. Criticou, igualmente, a aquisição do livro fotográfico Flagrantes do Brasil, que revelaria, em seu juízo, um país "primitivo", diferente do Brasil "moderno" que era preferível divulgar (Gonçalves, 1950). No campo do cinema, Jaime Sloan Chermont, outro chefe da DCI compartilhava dessa perspectiva. Ao analisar os preparativos para o envio do filme $\mathrm{O}$ Cangaceiro ao Festival de Cannes, solicitou ser incluída, no início da projeção, com destaque, a ressalva de que o cangaço fora extinto no Brasil (Chermont, 1953). Seu sucessor, José Oswaldo Meira Penna, criticou a participação brasileira no Festival de Filmes de Karlovy-Vary, na Tchecoslováquia, com a película Rio, 40ㅜ, por constituir "uma péssima imagem de nosso país" (Penna, 1959b). Em todos esses casos, nota-se uma estratégia de difusão cultural que remonta ao Barão do Rio Branco, no sentido de preconizar a difusão de uma imagem operacional do país no exterior,

\footnotetext{
${ }^{2}$ No Brasil, a diplomacia cultural é estudada academicamente pelo menos desde a década de 1940. Um dos temas de maior interesse foi a Missão Artística Francesa (ver como exemplo, Taunay, 1983). A melhor síntese sobre a história da diplomacia cultural brasileira é o artigo de Dumont \& Fléchet, 2014. Outra contribuição valiosa recente do ponto de vista conceitual é a de Gadelha, 2017. Duas coletâneas de ensaios apresentadas em catálogos de importantes exposições registram aportes substantivos para o arejamento do tema: Museu Nacional de Belas Artes, 1940; Brasil. MRE, 2018.
} 
independentemente de sua originalidade ou representatividade na cena cultural doméstica (Sevcenko, 1996, p. 124). De certo modo, a definição de Telles Ribeiro, hoje hegemônica, é tributária dessa concepção.

Havia, porém, outra interpretação de diplomacia cultural bastante em voga na chancelaria brasileira na década de 1960. Ela preconizava certa autonomia do campo cultural com relação ao político, seja por considerar a arte como elemento metafísico de deleite ou entretenimento ou por tomá-la como elemento monetizável no âmbito do desenvolvimento das indústrias culturais no período. Para este grupo, a diplomacia cultural deveria ser elemento integrante das relações internacionais culturais e ter mais autonomia com relação à política. As iniciativas da área deveriam refletir as aspirações dos campos culturais domésticos, mesmo que a imagem projetada apresentasse aspectos considerados negativos (violência, pobreza, desigualdade). Por fim, acreditavam no poder da arte de aproximar sociedades e promover o conhecimento mútuo e a paz.

Nascida oficialmente na Era Vargas na perspectiva de instrumento de propaganda estatal, a diplomacia cultural brasileira chegou à década de 1960 caracterizada por grande ênfase na abordagem de cunho político, algo particularmente visível, por exemplo, na instalação dos Painéis de Portinari na sede da ONU, na colaboração com a Bienal de Artes de São Paulo para sua internacionalização, na construção do Pavilhão do Brasil em Veneza ou no envio de professores ao Paraguai e a Bolívia, nestes dois últimos casos para conter intensa propaganda de Buenos Aires.

Inflexão importante nessa abordagem ocorreu com o advento da Política Externa Independente (1961-1964), adotada durante as gestões dos presidentes Jânio Quadros e João Goulart. Em 1961, os temas culturais, até então objeto de uma divisão (DCI) subordinada ao Departamento Político e Cultural, passam a ser tratados por um Departamento autônomo, contendo quatro divisões. Trata-se de mudança institucional relevante, pois traz à ordem do dia o dilema sobre até que ponto a diplomacia cultural deveria ser subordinada às áreas políticas e econômicas ou ter perfil mais autônomo. Para Lauro Escorel, primeiro diretor do novo Departamento, a reforma deu à área cultural autonomia sem precedentes (Escorel, 1961).

Paralelamente, verifica-se a ocorrência de um segundo embate no campo da diplomacia cultural brasileira, decorrente das tensões provocadas pela Guerra Fria no continente americano. A grande atração exercida pelo ideário comunista na classe artística brasileira do período acabaria desdobrando-se, na chancelaria brasileira, em um choque entre ocidentalistas e universalistas. No primeiro grupo, estavam diplomatas que temiam a aproximação com países comunistas por motivo de segurança e privilegiavam a aproximação com o que avaliavam, de forma hierárquica, como epítome civilizacional - Europa Ocidental e Estados Unidos. Meira Penna, um dos mais vocais defensores dessa corrente, chega ao ponto de sugerir a proibição da entrada de Charles Chaplin ao Brasil por ser "reconhecidamente comunista" e seu filme, Um Rei em Nova York, "um verdadeiro ataque aos Estados Unidos da América" (Penna, 1959a). Na seara musical, sua orientação 
anticomunista impediu a concessão de auxílio à pianista Anna-Stella Schic (1922-2009), filiada ao PCB em 1946. Para esse grupo, a promoção da obra de Villa-Lobos no exterior era a síntese máxima da contribuição da cultura brasileira ao mundo livre (Rodrigues, 2019, p. 248 e 256).

No segundo, estavam tanto diplomatas que simpatizavam com a causa comunista quanto aqueles de viés mais pragmático, que consideravam a cultura como campo autônomo e, por conseguinte, não viam maiores riscos à interação com países da órbita socialista. ${ }^{3}$ Esse grupo notabilizou-se pelo avanço na celebração de acordos culturais, pela promoção cultural brasileira no exterior (como as exposições sobre Brasília) e pela facilitação das atividades artísticas em território brasileiro - como o caso da visita da Ópera de Pequim no Brasil em 1956.

Nesse embate, a Política Externa Independente (PEI) novamente traz uma inflexão relevante, privilegiando os defensores de uma diplomacia cultural universalista. Justificada pelo princípio da autodeterminação dos povos, a PEI buscará avançar a agenda de relações culturais com regiões até então escassamente exploradas pela diplomacia brasileira. É nesse contexto que são abertos leitorados brasileiros ${ }^{4}$ no continente africano e enviadas exposições de arquitetura modernista a países da Cortina de Ferro, por exemplo.

Apesar desses embates, ou talvez por causa deles, a diplomacia cultural brasileira chega às vésperas do Golpe de 1964 com um portfólio admirável de realizações. No campo da arquitetura, contou com dezenas de exposições sobre o modernismo e obras emblemáticas, como os jardins de Burle Marx na sede da UNESCO. No campo do cinema, o país ganhou 22 prêmios em festivais internacionais de cinema entre 1962 e 1965 tornando-se, segundo cálculos do órgão, o país mais premiado proporcionalmente à sua produção anual (Mariz, 1965a). Nas artes plásticas, entre 1962 e 1964, o órgão apoiou mais de trezentas exposições artísticas no exterior (Vasconcellos, 1967). O apoio à internacionalização da Bossa Nova mostrava-se, igualmente, um grande êxito, tendo o disco Garota de Ipanema, de Antônio Carlos Jobim, ultrapassado rapidamente a casa do milhão de unidades vendidas no exterior. ${ }^{5}$ Nada indicava, portanto, ser necessária uma correção de rumos.

\section{Correção de rumos?}

O Golpe de 1964, entretanto, dará voz a setores que se mostravam refratários às diretrizes então vigentes para a diplomacia cultural brasileira. Desejavam, sobretudo, cortar os laços com indivíduos e pautas que consideravam contraproducentes à projeção internacional do país, como a arquiteta Lina Bo Bardi, que em visita a Roma foi considerada pelo embaixador Francisco D'Alamo Lousada "natural adversário do nosso atual regime" por conta de seu perfil político -- o que, naturalmente, reduziu suas chances de receber apoio governamental (Lousada, 1965). Do ponto de

\footnotetext{
${ }^{3}$ Sobre a questão universalismo/ocidentalismo na política externa brasileira, ver Nasser, 2017, Fonseca Jr., 2018 , p. 274.

${ }^{4}$ Programas de financiamento de professores para divulgar a cultura brasileira em universidades no exterior.

${ }^{5}$ Ver Nogueira, 1964 para relatório da área de música.
} 
vista do conteúdo artístico exibido no exterior, um diplomata da área cultural congratula-se, em 1966, pela "propagação de uma imagem do Brasil mais verdadeiro, em contraposição aos preconceitos que por vezes mal informam a opinião pública estrangeira" (Divisão de Difusão Cultural, 1966). Era esse tipo de avaliação subjetiva, que subordinava a cultura ao mundo da política e a um instrumento de propaganda, que começou a influenciar a tomada de decisão na área.

Curioso notar, no entanto, que o Golpe não modificou a estrutura do Departamento Cultural, de modo que a busca por inflexões ocorreu em outros níveis. A primeira e mais evidente verifica-se no âmbito dos servidores, com a valorização de diplomatas que partilhassem do ideário político do governo. Trata-se da desforra do grupo "ocidentalista", marginalizado no contexto da PEI. As mudanças se sucederam aos poucos, com a designação de Vasco Mariz para chefiar o Departamento Cultural; de José Osvaldo Meira Penna para a Secretaria-Geral para Assuntos da Europa Oriental, Ásia e Oceania; e de Manoel Pio Corrêa Júnior para a Secretaria-Geral. Todos os três já haviam atuado anteriormente na área cultural, sendo adeptos a um ocidentalismo excludente de interações com países comunistas.

Essa busca por inflexão pelas chefias foi particularmente nítida no campo do cinema. Vasco Mariz, a despeito de seu apoio inicial ao Cinema Novo, argumentou que os cineastas do movimento buscavam atender somente o gosto de estrangeiros pelo exótico, por uma visão construída do Brasil, sem se preocuparem com o mercado doméstico, que, segundo ele, pouco apreciaria o gênero (Mariz, 1965a). Meira Penna, que havia chefiado a DCI de 1956 a 1959, era ainda mais incisivo, registrando que obras como Ganga Zumba, do Cinema Novo, poderiam ser interessante para "simbas antropofágicos do Congo", sendo, todavia, péssima para ser apresentada, por exemplo, à família imperial japonesa, que deveria receber produtos condizentes (Penna, 1966).

Em linhas gerais, os novos gestores da diplomacia cultural brasileira também preconizavam uma perspectiva de propaganda. É sob esse prisma que Vasco Mariz entendeu ser a obra Deus e o Diabo na Terra do Sol uma sucessão de brutalidades de "resultado artístico duvidoso", estando próximo de "subversivo", além de grotescamente anticlerical, recomendando que se recolhessem as cópias de propriedade do Itamaraty no exterior (Mariz, 1965c). Meira Penna endossava essa visão. Após assistir ao filme O Pagador de Promessas, afirmou ser "peça de notório caráter subversivo" e propôs criar mecanismo de censura prévia no Itamaraty antes de enviar obras para embaixadas e consulados. Pio Corrêa concordou, afirmando que a avaliação da censura do Ministério da Justiça não era suficiente e que, além de afastar filmes que não retratassem bem o Brasil, era necessário avaliar o "ângulo político" de maneira cuidadosa, rejeitando "qualquer película que ofereça teor ideológico manifestamente subversivo". Daí a necessidade de uma "apreciação subjetiva" (censura adicional) para detectar "mensagem ideológica" (Penna, 1966).

Com essa inflexão das chefias, nota-se, junto aos servidores subordinados, um processo de perda de confiança e de espaço político para propor apoio a artistas e a obras, que culminaria com 
sutis, mas importantes transformações em suas rotinas de trabalho. O fenômeno da autocensura, por exemplo, caracterizaria bem a área no período. Com temor das chefias e de vetos externos dos militares, progressivamente deixou-se de apoiar personalidades avaliadas como controversas. Em uma lista de peças indicadas para tradução pela área cultural, por exemplo, um diplomata, antes de remetê-la ao Serviço Nacional de Informações (SNI), retirou os nomes de Nelson Rodrigues, Antonio Callado e Maria Clara Machado, sob a alegação de serem "personalidades já bem conhecidas" (Amado, 1965a, Amado, 1965b). No final de 1966, já há registro da existência de um "index" em que eram incluídos artistas críticos ao governo e que, por isso, não poderiam ser apoiados (Lima, 1966a). Isso significa que, nesse estágio, era muito difícil a promoção da obra de artistas que se posicionavam contra a Ditadura.

Foi natural, nesse contexto, o afastamento de muitos diplomatas que haviam trabalhado exitosamente no setor; elemento particularmente prejudicial, pois era justamente a rede de sociabilidades de servidores como Wladimir Murtinho, Lauro Escorel, Ruy Ribeiro Couto, Raul Bopp, Jayme de Barros, Vinícius de Moraes e outros - todos profundamente inseridos no meio artístico nacional - um dos fatores que contribuiram para o sucesso da diplomacia cultural brasileira no período. ${ }^{6} \mathrm{O}$ ambiente diminuiu as práticas informais essenciais que credenciavam os diplomatas junto ao campo artístico. Alguns foram demitidos, como Vinícius de Moraes, e outros voluntariamente pediram postos no exterior para se afastarem da política interna brasileira. São sintomáticas do desgaste gerado no campo as dificuldades em repor os quadros do Departamento Cultural com diplomatas alinhados ao regime. Em 1967, havia grave carência de servidores e apenas três dos seis setores da Divisão de Difusão Cultural tinham chefes ou encarregados (Vasconcellos, 1967).

A segunda inflexão ocorreu no âmbito das rotinas, havendo tentativa de concentração do processo decisório. Antes, embaixadores no exterior tinham certa autonomia na formulação do programa cultural dos postos. Vasco Mariz, assim que assumiu a chefia da Divisão de Difusão Cultural, criticou essa situação. Seu argumento direcionava-se à coerência da substância da diplomacia cultural, que, segundo ele, servia naquele momento mais para agradar artistas amigos do que realizar objetivos pré-determinados. Com vistas a diminuir o grau de discricionariedade dos postos e de servidores subordinados, a ditadura visou normatizar rotinas de consultas de obras e artistas, tanto externas, junto a órgãos militares, quanto internas, junto à alta chefia do Ministério. Everaldo Dayrell de Lima, Diretor do Departamento Cultural da época, já vislumbrava que esse processo tornaria o trabalho da área "insignificativo e pouco representativo dos (...) valores culturais [brasileiros]". ${ }^{7}$ Paradigmático exemplo desse novo momento foi a consulta estendida ao presidente Castelo Branco sobre a realização de exposição sobre Aleijadinho em Praga (Mariz, 1965b).

\footnotetext{
${ }^{6}$ Importante notar a natureza geracional dessa característica. Sobre gerações e redes de sociabilidade, ver Sirinelli, 1988.

${ }^{7}$ Citado em Mariz, 1964
} 
Epítome desse processo foi a criação da Divisão de Segurança e Informações (DSI) no Itamaraty (Decreto n. 60.463 14/3/1967), aparato da repressão instalado no âmago da diplomacia. A DSI notabilizou-se por impor rotinas e decisões à agenda da diplomacia cultural, responder pedidos de informação e questionamentos de órgãos militares e vetar o apoio a acadêmicos, artistas e estudantes considerados subversivos. Se, até então, a intervenção na diplomacia cultural era feita indireta e esporadicamente por órgãos militares, a partir de sua criação quase todo o fluxo de trabalho tramitaria pela unidade.

Esse contexto de autorregulação da diplomacia cultural brasileira para buscar servir aos interesses da Ditadura teve seu corolário na Comissão de Organização dos Serviços Culturais do Itamaraty, criada no governo Artur da Costa e Silva (1967-69) para reestruturar a diplomacia cultural. Presidida pelo diplomata e escritor João Guimarães Rosa, conhecido por seu conservadorismo político, o relatório da Comissão procurou centralizar as decisões e parametrizar as atividades de diplomacia cultural brasileira, por meio, sobretudo, da criação de uma Assessoria de Planejamento Cultural, reiterando uma concepção bastante politizada de diplomacia cultural (Brasil. MRE, 1967, p. 21). Sua proposta buscava, por um lado, seguir colhendo os bons frutos da difusão da imagem do Brasil no exterior, decorrentes da pujante produção cultural brasileira do período e, por outro, parametrizar essa difusão para que, sob o manto da tecnocracia, pudesse conter uma eventual imagem negativa no exterior em relação ao regime, que se poderia disseminar por meio de determinadas manifestações artísticas. Exemplos desse disciplinamento desdobram-se ao longo do relatório para todas as áreas da cultura, como no caso da música, em que se privilegiou a neutra música de concerto em detrimento da engajada $\mathrm{MPB}$, que se popularizava rapidamente no exterior desde o emblemático concerto de João Gilberto no Carnegie Hall em 1962. Outro exemplo eloquente foi no campo do cinema, em que se recomendou privilegiar vertente com "visão objetiva aliada a critério estético", apresentando "sem descuidar o gosto artístico, cobrir os diversos aspectos positivos da temática cultural brasileira". Recomendou-se, em particular, o "melhor ajustamento às intenções políticas de nossa ação cultural, com vistas a dar no exterior uma imagem consistente e amadurecida da vida nacional" (Brasil. MRE, 1967, p. 81). Importava nesse exercício menos a originalidade, qualidade e sucesso de artistas brasileiros no exterior do que o significado de suas expressões artísticas, que deveriam veicular uma edulcorada realidade brasileira no exterior.

Paralelamente a esse processo de normatização das rotinas da diplomacia, verifica-se um movimento de diluição do protagonismo do Itamaraty na área. A criação do Conselho Federal de Cultura e da Comissão de Seleção de Filmes Nacionais para Mostras Internacionais no Instituto Nacional do Cinema (INC), respectivamente em 1966 e 1967, reduziram a latitude de trabalho que detinha o órgão na articulação entre a produção cultural nacional e sua veiculação no exterior desde 1945.

Os ajustes nas chefias, privilegiando diplomatas que subordinavam a cultura ao mundo da política, e nas rotinas de trabalho, que tornaram o processo decisório bastante centralizado, 
contribuíram para uma terceira e expressiva mudança, relacionada ao conteúdo da cultura veiculada. Até 1964, nota-se a prevalência da convicção de que a arte deveria ser considerada como vetor de reflexão e transformação social. Por esse motivo, eram particularmente valorizadas iniciativas que veiculassem alto grau de sofisticação a respeito da realidade brasileira, mesmo que isso implicasse severas autocríticas, o que fica evidente, por exemplo, na promoção do Cinema Novo.

Sendo impossível, em um regime de exceção, sombrear as agruras por que passava a sociedade brasileira, a Ditadura buscou privilegiar a difusão de elementos culturais com baixo grau de engajamento político, como a arquitetura e o ensino da língua portuguesa, ou mesmo outros elementos de projeção da imagem do Brasil que extrapolam a difusão cultural, como a cooperação educacional e o futebol. Os episódicos sucessos da diplomacia cultural no período - como o apoio à construção do Pavilhão Brasileiro na Exposição Internacional de Osaka e a inclusão de Wilson Simonal, Jorge Ben e o Trio Mocotó no Festival Midem em Cannes, ambos em 1970 - amparam-se sobretudo em expressões artísticas pouco politizadas. Outra aposta da diplomacia cultural do período foi acentuar o valor econômico da cultura, em ações de promoção das indústrias criativas brasileiras, como no episódio em que o Itamaraty ofereceu, em 1968, à Direção da União Internacional de Arquitetos, em Paris, os móveis necessários à decoração dos principais gabinetes da chefia da União (Pinto, 1969b).

O ambiente no qual a diplomacia cultural operou, no Brasil e no exterior, era extremamente hostil ao governo; e o AI-5 radicalizou a ditadura e levou a medidas adicionais que impactavam a diplomacia cultural, como o decreto-lei n. 63.946, de 30 de dezembro de 1968, que determinava consultas ao presidente da República para autorização de saída do país de cada artista ou professor com ônus para o erário público. Vasco Mariz, na época chefe do Departamento Cultural, achou intolerável o novo regramento: "Parece-me ridículo incomodar o senhor Presidente com assuntos tão insignificantes" (Mariz, 1969). Até então, faziam-se consultas ao SNI, mas nunca o mérito da questão saía do Itamaraty - algo que anteriormente permitia aos diplomatas brasileiros alguma flexibilidade. Nesse ambiente, o espaço de discricionariedade da área cultural parecia ser muito estreito.

\section{Inércia e resistência}

A busca da ruptura com o padrão vigente de diplomacia cultural até 1964 não foi, no entanto, processo consensual, simples nem plenamente exitoso. Pioneiro indício de que diplomacia cultural esteve em passo fora da cadência ${ }^{8}$ da Ditadura foi o caso do maestro José Siqueira. Demitido da Ordem dos Músicos do Brasil por defender o ex-presidente João Goulart em um programa de rádio

\footnotetext{
${ }^{8}$ O termo "passo fora da cadência" foi cunhado por Amado Cervo para caracterizar a política externa do governo Castelo Branco (Cervo and Bueno, 2008).
} 
após o Golpe, Siqueira estava às vésperas de embarcar para Moscou em uma turnê pela Europa Oriental que envolveria 27 concertos patrocinados pelo Itamaraty. Mário Dias Costa, então chefe da DDC e diplomata que se notabilizara pelo programa de apoio à Bossa Nova nos Estados Unidos, ao tomar conhecimento da questão, propôs aos seus superiores a manutenção do programa sob o argumento de que era "atividade estritamente cultural", no que foi apoiado pelo seu chefe reforçando a tese de que a área deveria ser livre das amarras da área política (Costa, 1964). Foi o início de uma série de episódios que caracterizaram a resistência da área cultural à subordinação do mundo político. ${ }^{9}$

Nas mesmas três dimensões em que se operaram as mudanças com vistas a obter a almejada correção de rumos da política externa brasileira (servidores, institucionalidade e conteúdo), verificaram-se, igualmente, inércia e resistência por parte de diplomatas refratários ao novo regime. Do ponto de vista das chefias, a personagem emblemática que ilustra a resistência às acentuadas inflexões propostas pela Ditadura foi o diplomata Everaldo Dayrell de Lima, que assumiu o Departamento Cultural após o Golpe, posição na qual permaneceu até 1967, defendendo corajosamente a continuidade da diplomacia cultural no período e colecionando vitórias e derrotas. Ele abraçou a perspectiva pragmática da diplomacia cultural, desprovida de carga ideológica. ${ }^{10}$

Essa perspectiva se verifica na resposta que o diplomata faz a Pio Corrêa, com relação às críticas ao apoio concedido ao filme O Pagador de Promessas. Segundo Dayrell de Lima, a atuação da Comissão de Seleção de Filmes Brasileiros para Festivais Internacionais, presidida pelo Itamaraty, avaliava a obra "do ponto de vista estético, técnico e diplomático" e não a dimensão política e "dos bons costumes". ${ }^{11}$

Sua perspectiva encontrava eco junto a outros diplomatas da área. Vasco Mariz, por exemplo, construiu entendimento pessoal com o general Golbery do Couto e Silva para utilizar obras de artistas de esquerda, desde que não fossem enviados ao exterior (Mariz, 1969). Nesse contexto, Luiz Mattoso Maia Machado, ao selecionar peças teatrais que seriam vertidas para o idioma espanhol, incluiu obras de Antonio Callado, Nelson Rodrigues, Millor Fernandes, Oduvaldo Viana Filho e Jorge Andrade em lista encaminhada para o SNI avaliar "antecedentes políticos". Sobressai a escolha de nomes abertamente hostis à ditadura. Callado, por exemplo, havia pouco fora preso por militares no episódio do "Oito do Glória". No mês seguinte, a área tentou conceder apoio ao escritor Jorge Amado para o lançamento de uma peça em Lisboa, tendo seu nome sido vetado pelo SNI. Do mesmo modo, em dezembro de 1967, apesar de estar no index do órgão, um jovem diplomata atuando no

\footnotetext{
${ }^{9}$ Convém notar, no entanto, que Dias Costa foi removido da DDC para Roma em julho de 1964, praticamente não retornando para o Brasil antes de sua aposentadoria.

${ }^{10}$ Convém notar, aqui, inflexão do próprio diplomata, visto que no início da década opinou que o Brasil tinha uma diplomacia cultural em que predominavam "certos aspectos folclorísticos" e sugeriu privilegiar países como França, Portugal e Itália (Lima, 1962), à revelia, também, das diretrizes da diplomacia cultural da PEI.

${ }^{11}$ Ver comentário de Dayrell de Lima, datado de 31 de março de 1966, em Penna, 1966.
} 
setor recomendou o nome de Glauber Rocha para participar da Semana do Cinema Brasileiro no Museu de Arte Moderna de Nova York - convite vetado na recém-criada DSI (Oliveira, 1967).

Para esses diplomatas, a ênfase no ocidentalismo em vista da ameaça comunista não se justificava. Pelo contrário, representava amarras desnecessárias à projeção do Brasil no exterior. Dayrell de Lima era a voz mais loquaz na defesa do universalismo. Ao defender a manutenção de acordos culturais com países da Cortina de Ferro, sustentou que o Brasil não deveria realizar uma "cruzada ideológica" e tampouco temer uma "infiltração ideológica" comunista. Sua vitória, aqui, foi parcial. Os acordos foram mantidos, mas o Itamaraty privilegiou as trocas comerciais em detrimento de um programa cultural com esses países (Lima, 1964b, Lima, 1964a). Com o mesmo afinco, Maia Machado defendeu a participação brasileira no Festival Internacional de Moscou, em junho de 1965. Para ele, o país deveria aproveitar o "brilhante surto do Cinema Novo" e recomendou o envio de Glauber Rocha e Mário Carneiro. A medida foi aprovada pelos superiores sem muitas resistências, mas não foi possível identificar se o apoio passou pelo crivo dos militares e foi subvencionado (Amado, 1965d).

O extenso apoio concedido pelo Itamaraty ao Festival de Artes Negras de Dacar foi sinal significativo de que o Golpe não implicou o esvaziamento de uma política externa mais universalista. A participação brasileira foi preparada com "especial carinho" para a integração brasileira com a África, "que de forma tão decisiva conta, pelo número dos seus votos, em decisões tomadas no concerto das nações" (Ministério das Relações Exteriores, 1966, p. 18). Percebe-se, então, que aqui a visão universalista foi pautada não exclusivamente por interesse de difusão da cultura brasileira. Houve, no caso, influência de uma visão politizada da diplomacia cultural, vinculada à política de blocos do sistema internacional.

Do ponto de vista das rotinas institucionais, a centralização administrativa e uma melhor disseminação de informações sobre o perfil ideológico da classe artística diminuíram a discricionariedade de atuação dos diplomatas do setor cultural. Essas rotinas, entretanto, possuíam vulnerabilidades, sobretudo no início da Ditadura. Talvez o caso mais emblemático tenha sido a contratação, em 1965, do pintor Iberê Camargo para pintar o painel principal do saguão de entrada da sede da Organização Mundial da Saúde, em Genebra. O artista simpatizava com os que combatiam a Ditadura, mas seu perfil político não foi obstáculo para o convite e para a aceitação (Fundação Iberê Camargo, 2015, p. 247, Mariz, 1965e). Do mesmo modo, em setembro desse ano, sugeriu-se apoio ao cineasta Anselmo Duarte. A consulta ao Conselho de Segurança Nacional indicou que nada constava dele, a não ser o fato de que "recebia publicações comunistas do exterior" (Amado, 1965c). Ele já era, no entanto, ativo opositor dos militares.

Mesmo a tentativa de centralização sobre o que os postos no exterior estavam fazendo não foi plenamente bem-sucedida, como notou a diplomata Vera Sauer em um relatório de 1966, no qual criticou o "entusiasmo de realizações desordenadas" (Sauer, 1966). Conforme se apertava o cerco à 
discricionariedade, os diplomatas da área passaram a usar várias estratégias para defender seus projetos. A primeira foi tentar minimizar a oposição de artistas e acadêmicos à Ditadura. Quando o professor de história da arte José Roberto Teixeira Leite foi convidado a dar aula em Yale e o SNI recomendou o Itamaraty a vetar a emissão do passaporte, Dayrell de Lima tentou reverter a situação argumentando que tudo não passava de intrigas de uma claque acadêmica, e que Leite só seria "subversivo na imaginação desses profissionais do anticomunismo" (Lima, 1966b).

A segunda estratégia, a de acentuar a despolitização da cultura, era aplicada quando não era possível desassociar uma personalidade da oposição aos militares. Esse foi o caso quando o escritor Jorge Amado foi sugerido para o Prêmio Nobel de Literatura. Dayrell de Lima recorreu primeiramente à estratégia de minimizar a oposição de Amado à ditadura, recordando que, apesar de ter sido membro importante do Partido Comunista, havia se afastado de seus "antigos companheiros". Provavelmente percebendo que tal tese não convenceria seus superiores no Itamaraty, buscou então a rota da despolitização: "Parece-me óbvio que o Itamaraty deve prestigiar os valores culturais brasileiros, qualquer que seja a coloração política dos expoentes". Dois aspectos são significativos. Primeiro, sem esperar instruções dos superiores, tomou a iniciativa de entrar em contato com a Embaixada do Brasil em Estocolmo. Segundo, o linha-dura Pio Corrêa autorizou-o a entrar em contato com a Academia Brasileira de Letras e com o próprio escritor para indicar que o Itamaraty apoiaria o pleito (Lima, 1966b).

Ainda no âmbito da resistência à anodinização da diplomacia cultural brasileira, nota-se restrições por parte de diplomatas da área em abster-se de utilizar produtos culturais altamente engajados como vetor de projeção de uma cultura rica e sofisticada no Brasil, independentemente de suas colorações políticas. Isso fica particularmente evidente na área do cinema, uma das primeiras a sofrer com o afastamento da classe artística. Em carta aberta publicada ao Presidente da República no jornal Última Hora, em 1965, intelectuais e artistas alegaram que diplomatas estavam dificultando a apresentação de filmes brasileiros que retratassem a realidade do país em festivais internacionais (Lima et al., 1965). Vasco Mariz saiu em defesa do Itamaraty, notando que o órgão gastara milhares de dólares em tradução, promoção comercial e passagens para personalidades como Glauber Rocha, Luiz Carlos Barreto, Anselmo Duarte e Nelson Pereira dos Santos, todos signatários da carta (Mariz, 1965d).

De fato, foram muitos os episódios em que o Itamaraty atuou de maneira contrária às diretrizes gerais da Ditadura para promover o Cinema Novo no exterior, como no caso do filme $\mathrm{O}$ desafio, de Paulo César Saraceni. Havia digitais da diplomacia brasileira por toda a obra - ele recebeu uma bolsa do Itamaraty para estudar no Centro Experimental de Cinema em Roma em 1961; um dos filhos de Lauro Escorel, diretor do Departamento Cultural no governo Jango, montou os negativos do filme; e eram de autoria do diplomata Vinícius de Moraes duas músicas da trilha sonora. A obra, além de trabalhar com o conceito de luta de classes, fazia referência direta a torturas, prisões e inquéritos militares no Brasil pós-golpe. Saraceni solicitou apoio do Itamaraty para 
participar da exibição na mostra. A área cultural argumentou que diante do "prestígio" do filme, era aconselhável atender à solicitação, de modo que a diplomata Vera Sauer fez exitosas gestões junto à a área policial para liberar a exportação da obra - que acabou sofrendo cortes em trechos relacionados a questões políticas e à linguagem, algo que não prejudicou o filme, nem o impediu de ser o segundo mais votado pelo júri de críticos de Cannes (Neves, 1966). Glauber Rocha, crítico aberto do regime, foi outro cineasta que sempre logrou engajamento por parte de diplomatas da área cultural. Em 1965, por exemplo, quando seu filme Nordeste foi recusado pelo Festival de Cinema de Edimburgo por ser avaliado como excessivamente violento, partiu do Itamaraty a instrução para que a embaixada em Londres pressionasse os organizadores a reconsiderar a decisão, sinalizando inclusive que o Brasil poderia boicotar o festival (Brasil. MRE, 1965a). Mesmo no célebre caso da exibição de Terra em Transe no Festival de Cannes, em 1967, a despeito das alegações de falta de respaldo do órgão por parte de Glauber, as fontes indicam intensa articulação para viabilizar a projeção da película no Festival (Sauer, 1967).

Os argumentos da área cultural para defender atividades com alto grau de politização ficam claros no episódio que envolveu o convite da UNESCO para que Fernando Henrique Cardoso, professor aposentado pelo AI-5 e futuro presidente do Brasil, participasse de um evento acadêmico em 1969 - organismos internacionais acomodaram-se às demandas da ditadura de vetos a brasileiros. O chefe da Divisão de Difusão Cultural tomou a iniciativa de elencar quatro argumentos favoráveis ao apoio à UNESCO. O primeiro era que o "Brasil sempre gozou da reputação internacional de se guiar pelos princípios jurídicos válidos no mundo ocidental entre os quais o aforismo nulla pena sine lege" (sem lei, sem pena). O segundo era a impossibilidade de manter uma imagem externa artificial para a opinião pública internacional que fosse diferente de atos domésticos. Terceiro, havia uma demanda internacional por cérebros, atenta para indivíduos insatisfeitos. Por fim, indicou que ainda havia uma indefinição sobre as consequências do AI-5 em termos de diretrizes para a política externa. A cúpula foi sensibilizada, contudo, pela tese de que uma rejeição causaria "prejuízos ainda maiores à imagem do Brasil no exterior". Recomendou-se, então, a não objeção ao pedido (Lima, 1969).

Em alguns casos, porém, sequer eram necessários argumentos para defender a difusão de cultura altamente politizada, o que revela que o sistema de repressão sobre a diplomacia cultural brasileira talvez atuasse mais por conveniência do que por convicção. Exemplo paradigmático nesse sentido foi o apoio conferido pelo Itamaraty em 1966 ao Teatro Universitário de São Paulo (TUCA) para participar do Festival de Nancy, encenando a peça Morte e Vida Severina - de autoria do diplomata João Cabral de Melo Neto e musicada pelo compositor Chico Buarque. A apresentação ganhou $1^{\circ}$ lugar. Dois anos depois, o embaixador em Paris, Olavo Bilac Pinto, encaminhou demanda de auxílio financeiro ao Itamaraty no Rio de Janeiro para outra turnê do grupo. No Rio de Janeiro, a área cultural do órgão defendeu a subvenção, lembrando do prêmio de 1966. Indicaram, também, que a nova peça seria Os fuzis da senhora Carrar, de Bertolt Brecht, definida como "uma encenação 
moderna bastante ousada e original". O pedido tramitou incólume pelo Itamaraty e, submetido ao presidente Artur da Costa e Silva, como demandaram as novas regras, recebeu a autorização para o apoio. O caso é particularmente surpreendente pelo fato de ter ocorrido em período já maduro dos órgãos de repressão e que em toda sua cadeia de comunicação, da Embaixada em Paris à Presidência da República (onde recebeu assinatura do próprio presidente Costa e Silva) não encontrou qualquer indício de objeção (Pinto, 1969a).

\section{Conclusão}

A literatura até agora -- notadamente aquela referente aos anos iniciais da Ditadura -- tem salientado a dimensão de ruptura com o período anterior. Nesse artigo, focado na análise da trajetória da diplomacia cultural, foram apresentados muitos indícios de continuidades nas rotinas vigentes. Esse complexo quadro só pode ser explicado pelo exame dos dilemas próprios da área antes do Golpe e como a dinâmica política da Ditadura se inseriu nesse processo. Em outras palavras, deve-se buscar uma análise do campo cultural que não o considere mero epifenômeno de aspectos estruturais da política externa.

Apesar do forte processo de socialização da carreira, os diplomatas apresentam grande diversidade de compreensão sobre o conteúdo da diplomacia cultural. $O$ fato de não existir uma homogeneidade intelectual, aliás, parece ser chave interpretativa da maior utilidade, pois sugere que os processos de socialização e os constrangimentos institucionais da carreira diplomática não impedem a contestação e o choque entre indivíduos de tendências ideológicas distintas, mesmo durante a Ditadura. ${ }^{12}$

Outro ponto que sobressai da análise é a discricionariedade de ação dos diplomatas da área cultural. Nesse sentido, podem ser compreendidos como intelectuais intermediários que operam no âmbito estatal, alguns de forma independente e outros de forma orgânica, ou seja, como uma elite circunstancial estatal fragmentada que oferece liderança de natureza cultural ou ideológica para frações da sociedade, inclusive para a classe artística (O'Neill and Wayne, 2018, pp. 169-174). Eles ajudam a moldar a projeção internacional de poder imaterial, fundamentando o imaginário, as tecnologias e as organizações que oferecem coesão a classes e a blocos em torno de um uma identidade ou ideário comum no plano transnacional (Cox, 1983). Esse é um elemento que merece ser estudado com mais profundidade em futuras pesquisas.

O elemento central do argumento é a confirmação da existência de embates significativos sobre o que deveria ser a diplomacia cultural e sobre qual imagem o Estado brasileiro deveria projetar no mundo. A diplomacia cultural, portanto, deve ser vista como uma arena de contradições e choques e não como uma política pública coerente. Destacou-se, em particular, o embate sobre a

\footnotetext{
12 Sobre esse tema, ver Moura, 2007.
} 
função social da produção cultural: se deveria ser elemento de reflexão e engajamento social e, desse modo, subordinado à política, ou se a arte deveria ser concebida como um campo de entretenimento, concebida de forma mais autônoma e com isso abrindo a possibilidade de projetar no campo internacional uma imagem do Brasil com aspectos negativos, como a violência, a pobreza e a desigualdade.

Uma contribuição relevante do artigo é a tese de que a emergência de uma visão universalista da política externa brasileira, ou seja, a de que o Brasil deveria dialogar com outros sistemas políticos, provavelmente nasceu na área cultural. A batalha pela sua defesa após o Golpe de 1964 indica que talvez se tenha exagerado no argumento de que o governo Castelo Branco logrou realizar uma drástica ruptura com a política externa do governo anterior ao tentar se alinhar aos Estados Unidos e ao ocidentalismo.

É inegável que a Ditadura tenha tentado implementar uma nova visão de projeção da diplomacia cultural e buscado eliminar o apoio de artistas cujas preferências políticas e estéticas se chocavam com o grupo mais conservador. Os elementos empíricos apresentados indicam que houve espaço para a Ditadura tentar cooptar a classe artísticas, mas esse processo acabou fracassando. Isso gera interessante comparação com o Estado Novo (1937-45), que foi mais bem-sucedido em criar consensos e neutralizar a oposição da classe cultural, apropriando-se de obras e artistas. Três fatores contribuem para explicar essa dificuldade: maior autonomia do campo artístico do apoio estatal, em vista do desenvolvimento das indústrias culturais e das comunicações na década de 1960, que permitiu a criação de plataformas independentes para difusão artística; os entraves decorrentes dos processos de repressão e censura, que dificultam a promoção de uma imagem alternativa do país em audiências internacionais que prezavam temas como liberdades individuais, direitos humanos e expressões artísticas autênticas; e um rápido processo de ruptura na tradicional rede de sociabilidades entre o campo diplomático e o artístico, verificado no Itamaraty desde o século XIX, e que se iniciaria com a ditadura e se aceleraria com a transferência do Ministério das Relações Exteriores para Brasília em 1970, caracterizando um afastamento geográfico do campo diplomático com os eixos das indústrias culturais brasileiras.

Talvez esses mesmos fatores, entre continuidades e rupturas, tenham contribuído para que a diplomacia cultural nunca mais tenha alcançado o status que teve antes da Ditadura. Permanece, no entanto, mesmo nos dias atuais, a relevância da discussão sobre como apoiar artistas abertamente críticos ao governo. Igualmente relevante é discutir que tipo de imagem o Estado brasileiro deseja projetar para o mundo. Deseja-se construir uma versão asséptica e aspiracional, ou seria melhor reproduzir a complexidade de uma sociedade violenta e desigual? Essa dicotomia, não superada na Ditadura, tampouco mostra sinais de ter sido resolvida no período democrático, e sugere ser a diplomacia cultural uma das arenas de debates mais representativas dos diferentes valores e projetos políticos da sociedade brasileira. 


\section{Referências}

Amado, L. M. M. (1965a) Memo para Everaldo Dayrell de Lima. 15 de outubro. Brasília: Arquivo Histórico do Itamaraty (AHI-BSB).

Amado, L. M. M. (1965b) Memo para Everaldo Dayrell de Lima. 17 de dezembro. Brasília: AHI-BSB.

Amado, L. M. M. (1965c) Memo para Everaldo Dayrell de Lima. 27 de dezembro. Brasília: AHI-BSB.

Amado, L. M. M. (1965d) Memo para Everaldo Dayrell de Lima. Junho. Brasília: AHI-BSB.

Ang, I., Isar, Y. R., \& Mar, P. (2015). Cultural diplomacy: Beyond the national interest? International Journal of Cultural Policy, 21(4), 365-381.

Bado, A. R. L. (2006) A política econômica externa do governo Castelo Branco (1964-1967). Doutorado, Universiade de São Paulo, São Paulo.

Berridge, G. R. and Lloyd, L. (2012) The Palgrave Macmillan dictionary of diplomacy, 3rd edition ed., New York: Palgrave.

Brasil. MRE (1965a) Despacho telegráfico 392 para Embaixada em Londres. 3 de setembro. Brasília: AHI-BSB.

Brasil. MRE (1965b) Memo 184/SSN. Casa do Brasil em Madrid. Secreto. Brasília: Arquivo Nacional.

Brasil. MRE (1967) Relatório da Comissão Designada para Estudar a Organização dos Serviços Culturais. Reservado. Brasília: Ministério das Relações Exteriores.

Brasil. MRE (1968) C.P. 7.325. 5 de abril. Brasília: AHI-BSB.

Brasil. MRE (2018) The art of diplomacy: Brazilian Modernism painted for war, London: Embassy of Brazil in London.

Cervo, A. L. and Bueno, C. (2008) História da política exterior do Brasil. 3rd edn. Brasília: Editora Universidade de Brasília.

Chermont, J. S. (1953) IV Festival Internacional do filme, em Cannes. Participação do Brasil. 6 de fevereiro. Brasília: AHI-BSB.

Clarke, D. Cultural Diplomacy. Oxford Research Encyclopedia of International Studies. 2020.

Costa, M. D. (1964) Memo para Everaldo Dayrell de Lima. 30 de outubro. Brasília: AHI-BSB.

Couto, R. R. (1934) Informação ao Secretário-Geral. 1º de março. Brasília: AHI-BSB.

Cox, R. W. (1983) 'Gramsci, hegemony and international relations: an essay in method', Millennium, 12(2), pp. 162-175.

Cummings, M. C. (2009). Cultural diplomacy and the United States government: A survey (Cultural Diplomacy Research Series). Washington, DC.

Divisão de Difusão Cultural (1966) Relatório. Atividades culturais. Dezembro. Brasília: AHI-BSB.

Dumont, J. and Fléchet, A. (2014) '"Pelo que é nosso!": a diplomacia cultural brasileira no século XX', Revista Brasileira de História, 34(67), pp. 203-221.

Escorel, L. (1961) Memo para a Secretaria-Geral. 23 de novembro. Brasília: AHI-BSB. 
Farias, Rogério de Souza; Zétola, Bruno. Diplomacia cultural: uma arena de embates na Ditadura Militar

Falk, A. J. (2010) Upstaging the Cold War: American dissent and cultural diplomacy, 1940-1960. Amherst: University of Massachusetts Press.

Fonseca Jr., G. (2018) 'O pragmatismo responsável e a Guerra Fria', in Lima, S.E.M. (ed.) O pragmatismo responsável na visão da diplomacia e da academia. Brasília: FUNAG, pp. 245-280.

Fundação Iberê Camargo (2015) Iberê Camargo: século XXI. Porto Alegre: Fundação Iberê Camargo.

Gadelha, H. M. (2017) 'A diplomacia do futuro e a alcunha do passado: o mito do soft power brasileiro' in Westmann, G., ed. Novos Olhares sobre a política externa brasileira, São Paulo: Editora Contexto, pp. 103-113.

Goff, P. M. (2013). Cultural diplomacy. In A. F. Cooper, J. Heine, \& R. Thakur (Eds.), The Oxford handbook of modern diplomacy (pp. 1-19). Oxford, UK: Oxford University Press.

Gonçalves, R. M. (1950) Aquisição do livro de flagrantes do Brasil. 14 de março. Brasília: AHI-BSB.

Guimarães, M. (1952) Propaganda do Brasil no Peru. Memo para Vasco Leitão da Cunha. 23 de julho. Brasília: AHIBSB.

Lima, A. A., Niemeyer, O., Lins, Á., Secondi, F. P., Rodrigues, J. H., Viana, A. P. and Carreiro, T. (1965) 'Carta aberta ao Presidente da República: intelectuais e artistas pela liberdade', Última Hora, 10 de agosto, p. 7.

Lima, E. D. d. L. (1962) Memo para Aluysio Régis Bittencourt. 17 de abril. Brasília: AHI-BSB.

Lima, E. D. d. L. (1964a) Memo para A. B. Castello Branco. 5 de novembro. Brasília: AHI-BSB.

Lima, E. D. d. L. (1964b) Memo para A. B. Castello Branco. 20 de setembro. Brasília: AHI-BSB.

Lima, E. D. d. L. (1966a) Memo para A. B. Castello Branco. 23 de dezembro. Brasília: AHI-BSB.

Lima, E. D. d. L. (1966b) Memo para Manoel Pio Corrêa. 7 de março. Brasília: AHI-BSB.

Lima, N. L. d. S. L. (1969) Memo para Osmar Vladimir Chohfi. 13 de junho. Brasília: AHI-BSB.

Lousada, F. D. A. (1965) Ofício 180 de BrasembRoma. 8 de março. Confidencial. Brasília: AHI-BSB.

Mariz, V. (1964) Memo para Everaldo Dayrell de Lima. 7 de dezembro. Brasília: Ministério das Relações Exteriores.

Mariz, V. (1965a) Memo para Everaldo Dayrell de Lima. 5 de abril. Brasília: AHI-BSB.

Mariz, V. (1965b) Memo para Everaldo Dayrell de Lima. 8 de janeiro. Brasília: AHI-BSB.

Mariz, V. (1965c) Memo para Everaldo Dayrell de Lima. 8 de março. Brasília: AHI-BSB.

Mariz, V. (1965d) Memo para Everaldo Dayrell de Lima. 11 de agosto. Brasília: AHI-BSB.

Mariz, V. (1965e) Memo para Everaldo Dayrell de Lima. 14 de janeiro. Brasília: AHI-BSB.

Mariz, V. (1969) Memo para para Gibson Barboza. 31 de outubro. Brasília: AHI-BSB.

Mark, S. L. (2010) 'Rethinking cultural diplomacy: The cultural diplomacy of New Zealand, the Canadian Federation and Quebec', Political Science, 62(1), pp. 62-83.

Martins, C. E. (1975) 'A evolução da política externa brasileira na década 64/74', Novos Estudos CEBRAP, 12, pp. 55-98.

Ministério das Relações Exteriores (1966) Relatório. Rio de Janeiro: Departamento de Administração.

Moura, C. P. d. (2007) O Instituto Rio Branco e a diplomacia brasileira: um estudo de carreira e socialização. Rio de Janeiro: Editora FGV. 
Farias, Rogério de Souza; Zétola, Bruno. Diplomacia cultural: uma arena de embates na Ditadura Militar

Museu Nacional de Belas Artes (1940) Exposição da missão artistica francesa de 1816, Rio de Janeiro: Ministério da Educação e Saúde.

Nasser, F. (2017) 'Brasil Tous Azimuts. Um ensaio sobre os significados do princípio do universalismo para a política externa brasileira', Cadernos do IPRI, III(6), pp. 27-62.

Neves, D. E. (1966) Memo para Everaldo Dayrell de Lima. 25 de abril. Brasília: AHI-BSB.

Nogueira, E. G. (1964) Memo para Mário Dias Costa. 4 de agosto. Brasília: AHI-BSB.

O'Neill, D. and Wayne, M. (2018) On intellectuals. Considering class: theory, culture and the media in the 21st century Leiden; Boston: Brasiliense.

Oliveira, N. Á. G. d. (1967) Memo para Celso Diniz. 29 de dezembro. Brasília: AHI-BSB.

Penna, J. O. M. (1959a) Memo para chefe do DPC. 16 de abril. Brasília: AHI-BSB.

Penna, J. O. M. (1959b) Participação do Brasil no Festival de Cinema de Karlovy-Vary, na Tchecoslováquia. 13 de abril. Brasília: AHI-BSB.

Penna, J. O. M. (1966) Memo para Manoel Pio Corrêa. 18 de março. Brasília: AHI-BSB.

Pinto, J. d. M. (1969a) Informação ao Presidente da República. 2 de abril. N. 210. Brasília: AHI-BSB.

Pinto, J. d. M. (1969b) Informação ao Presidente da República. 9 de janeiro. N. 20. Brasília: AHI-BSB.

Ribeiro, E. T. (2011) Diplomacia cultural: seu papel na política externa brasileira. Brasília: Fundação Alexandre de Gusmão.

Rodrigues, P. H. B. (2019) O maestro no mundo. Doutorado, Universidade Federal Fluminense, Niterói (RJ).

Sauer, V. R. A. (1966) Informações sobre o andamento dos trabalhos da DDC. 12 de maio. Brasília: AHI-BSB.

Sauer, V. R. A. (1967) Memo para SSN. 7 de março. Brasília: AHI-BSB.

Schneider, C. P. (2006) 'Cultural diplomacy: Hard to define, but you'd know it if you saw it', The Brown journal of world affairs, 13(1), pp. 191-203.

Sevcenko, N. (1996) Literatura como missão: tensões sociais e criação cultural na Primeira República. 2. edn. São Paulo: Brasiliense.

Silva, A. L. R. d. (2004) A diplomacia brasileira entre a segurança e o desenvolvimento: a política externa do governo Castelo Branco (1964-1967). Porto Alegre: Editora da UFRGS.

Sirinelli, J.-F. (1988) Génération intellectuelle. Khâgneux et Normaliens dans l'entre-deux-guerres. Paris: Fayard.

Taunay, A. d. E. (1983) A missão artística francesa de 1816. Brasília: Editora da Universidade de Brasília.

Vasconcellos, A. (1967) Memo para Ovídio de Andrade Melo. 30 de junho. Brasília: AHI-BSB.

Zamorano, M. M. (2016). Reframing cultural diplomacy: The instrumentalization of culture under the soft power theory. Culture Unbound, 8(2), 165-186. 